\title{
1 Modeling of Heat Extraction from 2 Variably Fractured Porous Media in 3 Enhanced Geothermal Systems
}

\section{Teklu Hadgu*, Elena Kalinina and Thomas S Lowry}

Sandia National Laboratories, MS 0747, P.O. Box 5800, Albuquerque, NM 87185, USA

thadgu@sandia.gov, eakalin@sandia.gov, tslowry@sandia.gov

\section{Abstract}

Modeling of heat extraction in Enhanced Geothermal Systems is presented. The study builds on recent studies on the use of directional wells to improve heat transfer between doublet injection and production wells. The current study focuses on the influence of fracture orientation on production temperature in deep low permeability geothermal systems, and the effects of directional drilling and separation distance between boreholes on heat extraction. The modeling results indicate that fracture orientation with respect to the well-pair plane has significant influence on reservoir thermal drawdown. The vertical well doublet is impacted significantly more than the horizontal well doublet.

Keywords: reservoir modeling, enhanced geothermal systems, heat extraction, fractured orientation, well orientation, stochastic methods 


\section{Introduction}

23 Enhanced Geothermal Systems (EGS) have the potential to extract heat in low permeability 24 fractured rock in locations largely unsuitable for conventional hydrothermal systems. EGS 25 allows extraction of heat through natural reservoirs with suitable permeability or stimulated 26 reservoirs where permeability and heat transfer area are mechanically or chemically enhanced.

27 The economic viability of EGS is dependent on variables such as drilling costs, initial reservoir 28 temperature, decrease in temperature during the operational time (thermal drawdown), and 29 fracture permeability. Understanding the relationships and dependencies between these variables will enable developers to optimize system design to increase viability and reduce economic risk.

31 Estimation of extraction of heat from fractured geothermal reservoirs has been a subject of study

32 for decades. Gringarten et al. (1975) used mathematical models to produce analytical solutions to 33 predict heat extraction from fractures in hot dry rock using injection and withdrawal wells. The 34 authors investigated the use of directional drilling to optimize heat extraction based on 35 orientation of fractures. Similar studies using the analytical method were conducted by other 36 researchers (Gringarten and Sauty, 1975; Cheng et al., 2001; Ghassemi et al. 2003; Yang and 37 Yeh, 2009). To overcome the limitations of the analytical solutions (dimensionality and constant parameter values) various numerical models have been developed to study the effect of fracture 39 characteristics on reservoir behavior (Juliusson and Horne, 2010; Hao et al., 2013; Doe et al., 40 2014). The various numerical models use different mathematical models designed for specific 41 applications. The majority of the EGS studies consider the vertical wells. Only a few studies 42 evaluated horizontal wells (Shiozawa and McClure, 2014). Our study provides in depth analysis 43 of both, vertical and horizontal wells. 
45 Previous studies have looked at thermal performance and economic evaluation of the use of 46 directional wells for EGS (Lowry et al., 2014, Kalinina et al., 2014a and 2014b) and showed that

47 well orientation played an important role in thermal drawdown with the most advantageous 48 configuration consisting of a horizontal well-pair with the injection well below the production 49 well. The economic viability was highly influenced by the drilling and pumping costs, the latter 50 being a function of the effective permeability between the wells.

51 For this study the Fracture Continuum Method (FCM) was used to develop stochastic 52 representations of reservoir permeability. The FCM was developed by McKenna and Reeves 53 (2006) to generate multiple permeability fields using field observations of fracture set data. The 54 method was later enhanced by adding anisotropy using the approach of Chen et al. (1999). 55 Applications of the FCM method to modeling EGS are reported in recent publications (Kalinina 56 et al. 2012a, 2012b, 2014a, 2014b). The FCM does not need upscaling because the REV-size 57 grid blocks used are sufficiently small. McKenna and Reeves (2005) recommended that the size 58 of the numerical model grid blocks to be kept small enough that fracture properties can be 59 assumed constant over the size of the grid block. The constant grid block size and the fracture 60 properties used in this study are in line with the recommendation of McKenna and Reeves 61 (2006). Hao et al. (2013) showed that the output of a continuum model is comparable to that 62 from a discrete fracture model.

63 The method of Chen et al. (1999) allows representation of multiple fracture sets for different 64 fracture orientations. FCM maps the permeability of discrete fractures onto a regular grid using a 65 continuum approach. This approach defines fracture sets using distributions of strike, dip, 
66 aperture, and spacing of parallel fractures in the system. The permeability tensor of Chen et al.

67 (1999) defines permeability for each grid cell in the model domain. For one fracture set, the

68 permeability tensor is given as:

$69 \quad k_{i j}=\frac{b^{3}}{12 d}\left[\begin{array}{ccc}\left(n_{2}\right)^{2}+\left(n_{3}\right)^{2} & -n_{1} n_{2} & -n_{3} n_{1} \\ -n_{1} n_{2} & \left(n_{3}\right)^{2}+\left(n_{1}\right)^{2} & -n_{2} n_{3} \\ -n_{3} n_{1} & -n_{2} n_{3} & \left(n_{1}\right)^{2}+\left(n_{2}\right)^{2}\end{array}\right]$,

70 where $k_{i j}$ is the permeability tensor in the $i=x, y, z$ and $j=x, y, z$ directions, $b$ is fracture aperture, $d$

71 is fracture spacing, and $n_{1,2,3}$ is the unit normal to the fracture plane in the $x, y$, and $z$ direction,

72 respectively.

73 The unit normal components to the fracture plane are defined as:

$74 \quad n_{1}=\operatorname{Cos}\left(\alpha \frac{\pi}{180}\right) x \operatorname{Sin}\left(\omega \frac{\pi}{180}\right)$

$75 \quad n_{2}=\operatorname{Cos}\left(\alpha \frac{\pi}{180}\right) x \operatorname{Cos}\left(\omega \frac{\pi}{180}\right)$

$76 \quad n_{3}=-\operatorname{Sin}\left(\alpha \frac{\pi}{180}\right)$

77 where $\alpha=90^{\circ}-\operatorname{dip}$ and $\omega=$ strike $-90^{\circ}$. The permeability tensor represents permeability

78 anisotropy. Note that only the principal components $\left(k_{x x}, k_{y y}\right.$, and $\left.k_{z z}\right)$ of the permeability tensor

79 are used in the heat transport model. This assumes that the $x, y$, and $z$ coordinate directions

80 coincide with the principal directions of anisotropy, as used in anisotropic groundwater flow

81 models (Bear, 1972; Freeze and Cherry, 1979).

82

83 In the case of multiple fracture sets, the permeability tensor can be computed by adding the

84 permeability tensors for individual fracture sets as follows.

$85 \quad k_{i j}=\sum_{m=1}^{N} k_{i j}^{m}$ 
87 where $N$ is the number of fracture sets and $k_{i j}{ }^{m}$ is defined by Eq. (1). The summation assumes

88 that the total porosity within a grid-cell changes very little, which is valid for most EGS

89 conditions.

90 The $k_{x x}{ }^{m}, k_{y y}{ }^{m}$ and $k_{z z}{ }^{m}$ values are calculated for each grid block based on the parameters of

91 fracture aperture, spacing, strike, and dip probability distributions that are defined for each

92 fracture set $m$.

93 The FCM is also applicable to cases where fracturing varies with depth. For such cases the FCM

94 is applied to separate zones at different depths.

97 Thermal-hydrologic simulations were carried out to study the effect of fracture parameters, well 98 orientation, and well separation distance on heat extraction in an EGS system. The focus is on 99 understanding the effect of fracture orientation (i.e. strike and dip), well separation distance and 100 well orientation on EGS heat extraction to support decision making on drilling and fracture 101 enhancement methods. Note that geomechanical effects were assumed to be negligible during the 102 injection/production phase of an EGS that is either naturally fractured or stimulation has been 103 completed. For a large reservoir and injection/production period of decades, such as used in this 104 study, geomechanical effects were assumed to be minimal thus were not included (see also 105 Bachler and Kohl, 2005).

106 For the analysis a representative EGS system was developed to simulate thermal conditions in a 107 geothermal system. The numerical simulator FEHM was used for thermal-hydrologic 
108 simulations (Zyvoloski et al. 1997). FEHM is a control volume finite element code for 109 simulating subsurface non-isothermal multi-phase, multi-fluid heat and mass transfer. The 110 numerical code has been extensively used for modeling geothermal systems, groundwater flow, 111 and flow and transport for nuclear waste disposal applications. FEHM assumes Darcy's law is 112 applicable for fluid flow, and that thermal equilibrium exists between fluid and rock (locally).

113 Other assumptions include an immovable rock phase and negligible viscous heating. Below is a 114 description of the mass and energy balance equations used by FEHM.

115 Conservation of mass for water is described as:

$116 \frac{\partial A_{m}}{\partial t}+\bar{\nabla} \cdot \overline{f_{m}}+q_{m}=0$

117 where the mass per unit volume, $A_{m}$, is given by:

$118 A_{m}=\varphi\left(S_{v} \rho_{v}\left(1-\eta_{v}\right)+S_{l} \rho_{l}\left(1-\eta_{l}\right)\right)$

119 and the mass flux, $\overline{f_{m}}$ is given by:

$\overline{f_{m}}=\left(1-\eta_{v}\right) \rho_{v} \bar{V}_{v}+\left(1-\eta_{l}\right) \overline{v_{l}} \rho_{l}$

120 where, $\phi$ is the porosity of the matrix, $S$ is saturation, $\rho$ is density, $\eta$ is the concentration of the 121 noncondensible gas and is expressed as a fraction of the total mass, $\bar{v}$ is velocity, and the 122 subscripts $v$ and $l$ indicate quantities for the vapor phase and the liquid phase, respectively.

123 Source and sink terms are represented by the term $q_{m}$.

125 Conservation of fluid-rock energy is described as: 
$126 \frac{\partial A_{e}}{\partial t}+\bar{\nabla} \cdot \bar{f}_{e}+q_{e}=0$

127 where the energy per unit volume, $A_{e}$, is given by:

$128 A_{e}=(1-\varphi) \rho_{r} u_{r}+\varphi\left(S_{v \rho} \rho_{v} u_{v}+S_{l} \rho_{l} u_{l}\right), u_{r}=c_{p r} T$

129 and the energy flux, $\bar{f}_{e}$ is given by:

$130 \quad \bar{f}_{e}=\rho_{v} h_{v} \overline{V_{v}}+\overline{v_{l}} \rho_{l} h_{l}-K \bar{\nabla} T$

131 The subscript $r$ refers to the rock matrix, $u_{r}, u_{v}$, and $u_{l}$ are specific internal energies, $c_{p r}$ is the 132 specific heat, $h_{v}$, and $h_{l}$ are specific enthalpies, $K$ is an effective thermal conductivity, $T$ is the 133 temperature, and $q_{e}$ is the energy contributed from sources and sinks.

134 It is assumed that Darcy's Law applies to the movement of each phase and the velocity can be 135 expressed as:

$136 \quad \overline{v_{v}}=\frac{k R_{v}}{\mu_{v}}\left(\bar{\nabla} P_{v}-\rho_{v} \bar{g}\right)$

$137 \quad \bar{v}_{l}=\frac{k R_{l}}{\mu_{l}}\left(\bar{\nabla} P_{l}-\rho_{l} \bar{g}\right)$

$138 P_{v}=P_{l}+P_{c a p}$

139 where $k$ is the permeability, $R_{v}$, and $R_{l}$, are the relative permeabilities, $p_{v}$ and $p_{l}$ are viscosities, $P_{v}$ 140 and $P_{1}$ are the phase pressures, $P_{\text {cap }}$ is the capillary pressure and $\bar{g}$ represents the acceleration 141 due to gravity. 
144 For the study the reservoir is assumed to be at a depth of $4 \mathrm{~km}$. The model geometry is $1605 \mathrm{~m} \mathrm{x}$ $435 \mathrm{~m}$ in the horizontal direction and $1605 \mathrm{~m}$ in the vertical direction. The three-dimensional

146 mesh consists of a structured grid with 332,021 elements (349,920 nodes) and a constant grid

147 block size of $15 \mathrm{~m} \times 15 \mathrm{~m}$ x $15 \mathrm{~m}$ (Figure 1$)$.

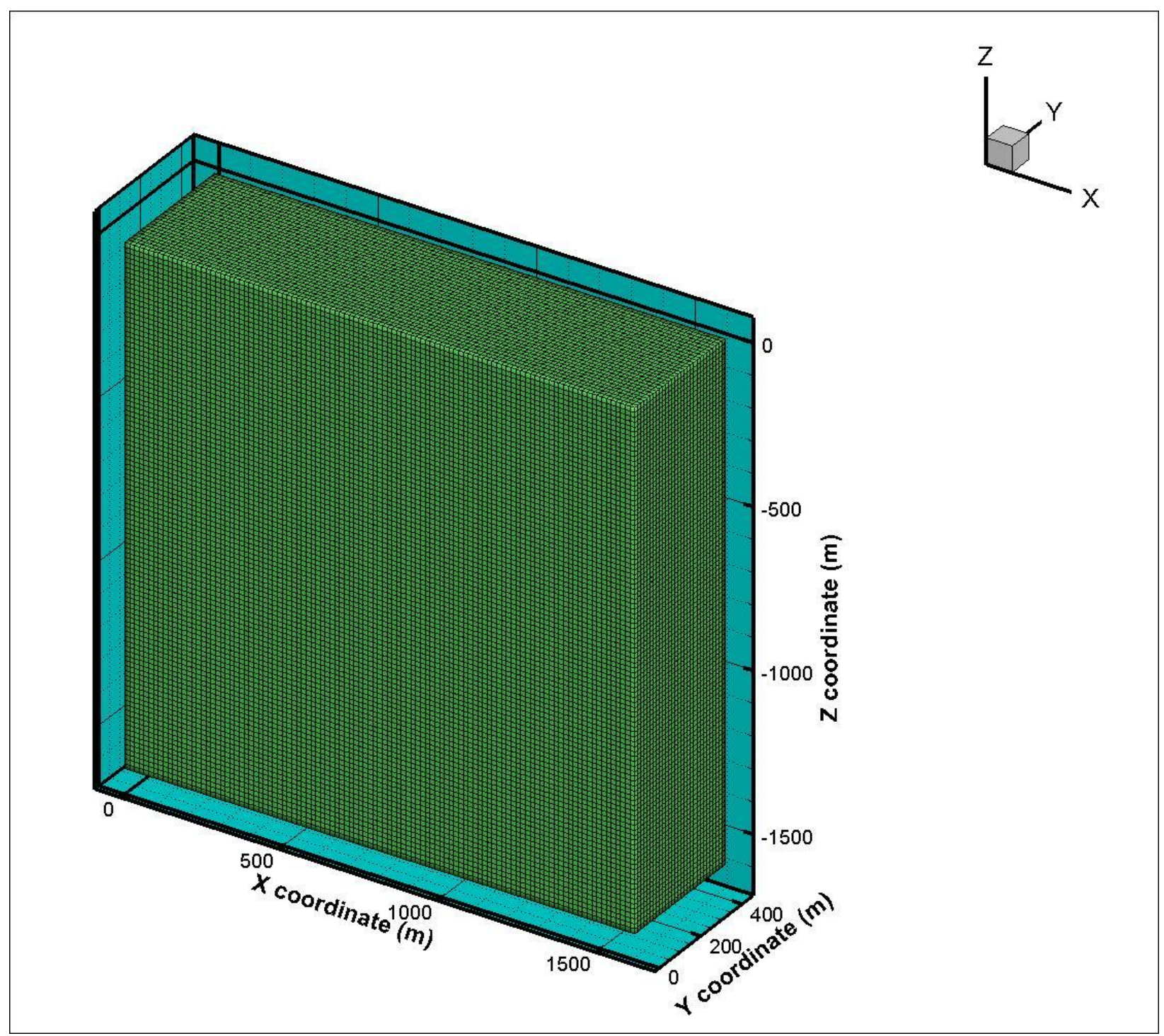

149 Figure 1: Geometry and meshing of the model domain 
151 The geothermal system is assumed to be at an initial condition of hydrostatic pressure at the 152 corresponding depth and a constant temperature of $200{ }^{\circ} \mathrm{C}$. The boundary conditions use 153 constant temperature $\left(200^{\circ} \mathrm{C}\right)$ and pressure (hydrostatic) on all sides except the bottom, which 154 assumes zero flux for both mass and heat. Water injection is implemented using a fixed injection 155 mass-flow rate of $50 \mathrm{~kg} / \mathrm{s}$ and injection temperature of $80{ }^{\circ} \mathrm{C}$. Production is from a production 156 well that uses a fixed bottom-hole pressure that maintains the $50 \mathrm{~kg} / \mathrm{s}$ mass-flow rate and 157 provides a production draw-down pressure. The injection/production well-pair were modeled in 158 both vertical and horizontal configurations with identical screened intervals. Rock properties 159 include rock grain density of $2850 \mathrm{~kg} / \mathrm{m}^{3}$, porosity of 0.01 , thermal conductivity of $3 \mathrm{~W} / \mathrm{m} \mathrm{K}$, 160 and specific heat of $950 \mathrm{~J} / \mathrm{kg} \mathrm{K}$.

161 Fracture properties are statistically represented in the FCM using distributions of parameters. 162 The probability distributions for the fracture parameters were developed based on the fracture 163 properties common for granitic rocks, which have been studied worldwide for many different 164 applications. The different applications include mining (quarry development), contaminant 165 transport, oil and gas exploration and geologic disposal of radioactive waste. A literature review was conducted to compile the fracture data from these various studies. When possible, 167 information on fracture orientation, dip, spacing, aperture and length was collected. The results 168 of this review are documented in Kalinina et al. (2012a).

170 For this study fracture spacing was represented using an exponential probability distribution with 171 a rate parameter $(\lambda)$ value of 1 , and the distribution was taken over the span of $0.1 \mathrm{~m}$ and $15 \mathrm{~m}$. 172 Fracture aperture is modeled using a normal probability distribution with mean of $0.1 \mathrm{~mm}$ and a 173 standard deviation of $0.01 \mathrm{~mm}$. In the study the mean values of fracture spacing and aperture 
were kept constant. But the mean values of fracture strike and dip were varied. The strike and dip angles of the mean fracture planes were varied using a normal distribution and means of 5, 33, $61,89,117,145$, and 173 degrees for the strike and 5, 18, 31, 44, 57, 70, and 83 for the dip. The standard deviation was set at 3 degrees across all angles of strike and dip. It should be noted that a dip of zero degrees corresponds to a horizontal fracture plane and a strike of zero degrees means the fracture plane is parallel to the plane of the well-pair. A graphical representation of parameter distributions are given in Figure 2. Well separation distances of 495 and $600 \mathrm{~m}$ were used for both the horizontal and vertical well configurations. The 'base case' assumes a separation distance of $495 \mathrm{~m}$. A production/injection interval of $250 \mathrm{~m}$ was used. For the horizontal well configuration, the production well is above the injection well. The thermal and hydrologic conditions are simulated over a 30 year time-span to correspond with the typical lifetime of a geothermal power plant. Table 1 is a list of inputs that were varied, the statistical model used to represent them (if applicable), and the parameter and/or input values. Figure 3 is a representative three-dimensional plot of a permeability calculated with the FCM approach using a mean strike and dip of 5 and 44 degrees, respectively.

Table1: Parameter models and variations used in the FEHM simulations.

\begin{tabular}{|l|l|l|l|l|}
\hline \multicolumn{1}{|c|}{ Variable } & Distribution & \multicolumn{1}{|c|}{ Parameters } & \multicolumn{1}{c|}{ Units } & \multicolumn{1}{c|}{ Comments } \\
\hline Fracture Spacing & Exponential & $\lambda=1$ & $\mathrm{~m}$ & $\begin{array}{l}\text { Truncated to a } \\
\text { minimum of } 0.1 \\
\text { m and a } \\
\text { maximum of } 15 \\
\mathrm{~m} .\end{array}$ \\
\hline Fracture Aperture & Normal & $\begin{array}{l}\mu=0.1 \\
\sigma=0.01\end{array}$ & $\mathrm{~mm}$ & \\
\hline Strike & Normal & $\begin{array}{l}\mu=5,33,61,89, \\
117,145,173 \\
\sigma=3\end{array}$ & Degrees & $0^{\circ}=$ horizontal \\
& & & \\
\hline
\end{tabular}




\begin{tabular}{|l|l|l|l|l|}
\hline Dip & Normal & $\begin{array}{l}\mu=5,18,31,44, \\
57,70,83 \\
\sigma=3\end{array}$ & Degrees & $\begin{array}{l}0^{\circ}= \\
\text { perpendicular to } \\
\text { the well-pair } \\
\text { plane. }\end{array}$ \\
\hline Well Spacing & NA & 495,600 & $\mathrm{~m}$ & \\
\hline $\begin{array}{l}\text { Production/Injection } \\
\text { Interval }\end{array}$ & NA & 250 & $\mathrm{~m}$ & $\begin{array}{l}\text { Production and } \\
\text { injection use } \\
\text { same interval }\end{array}$ \\
\hline Mass Flow Rate & NA & 50 & $\mathrm{~kg} / \mathrm{s}$ & \\
\hline
\end{tabular}
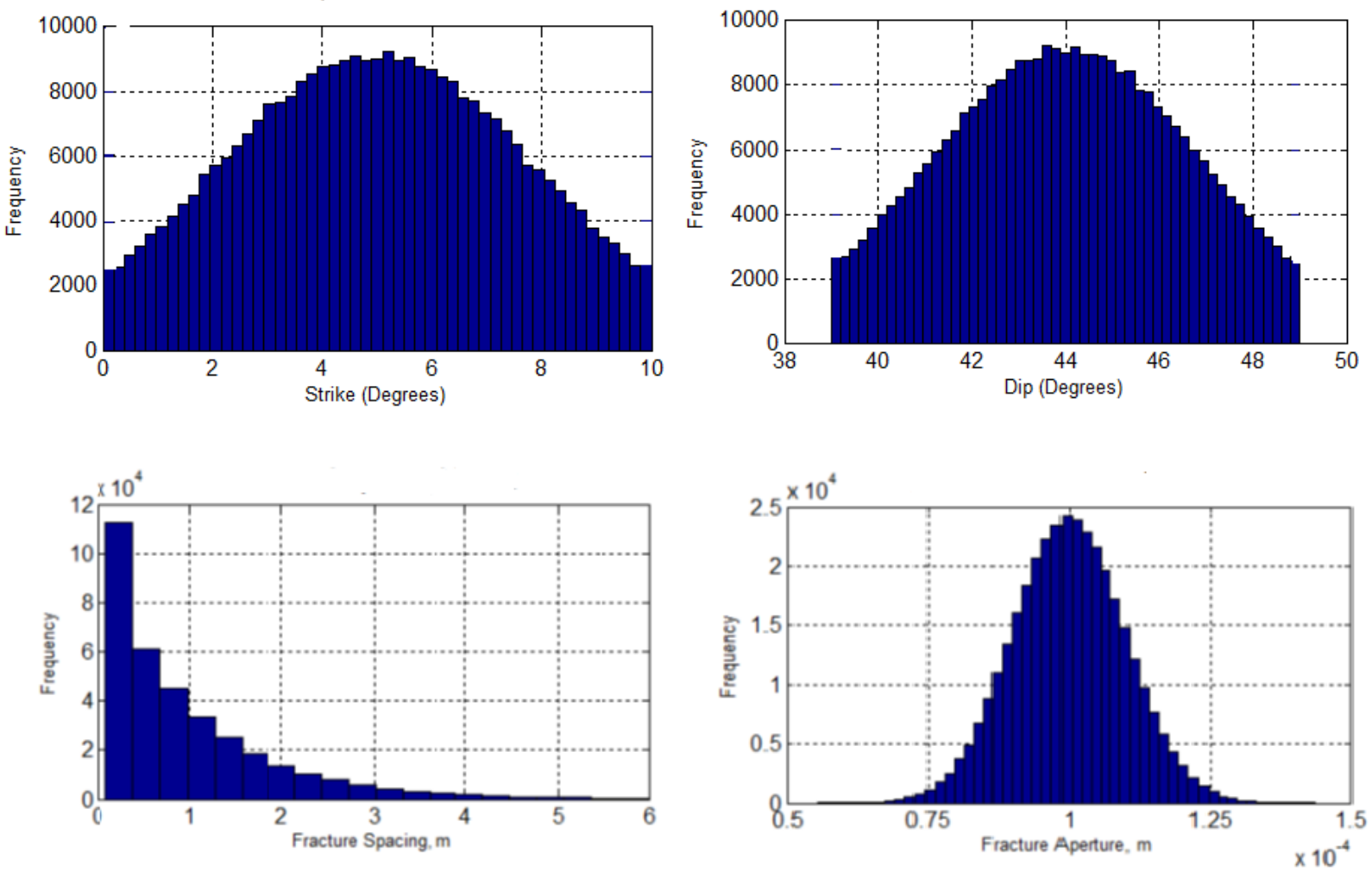

NOTE: The fracture spacing and aperture probability distributions are the same for all the cases while fracture strike and dip probability distributions are case dependent.

194 Figure 2. Simulated Values of Fracture Strike, Dip, Spacing, and Aperture for the $5^{0}$ Strike and $44^{0}$ Dip Case. 
$\log 10 \mathrm{Kyy}(\mathrm{m} 2)$
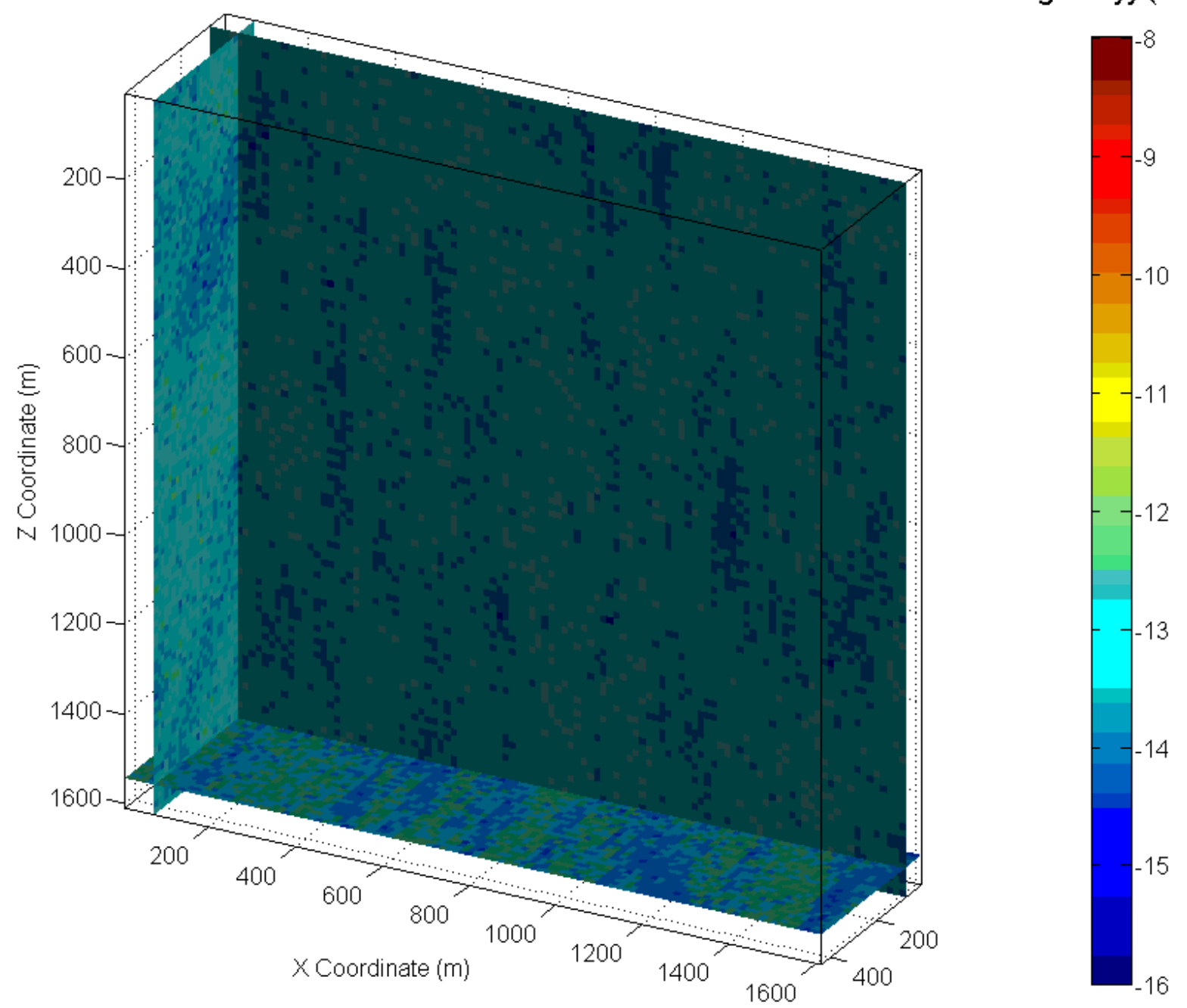

198 Figure 3: FCM generated permeability field with the following fracture properties. Strike: 199 normal distribution with mean $5^{\circ}$, and Dip: normal distribution with mean $44^{\circ}$.

\section{Results and Discussion}

202 Figure 4 shows the effective permeability in the x-direction (i.e., along the well-pair plane) as a 203 function of the strike and dip for the base case (Equations 2a, b). At low dip angles, the 204 permeability values are insensitive to the strike angle. However, as the dip angle increases the 205 permeability decreases as the strike angle nears $0 / 180$ degrees. Figure 5 shows the effective 
206 permeability in the z-direction (i.e., vertical) as a function of the strike and dip for the base case 207 (Equation 2c). Not surprisingly, the vertical permeability is insensitive to the strike angle and 208 increases as the dip angle decreases.

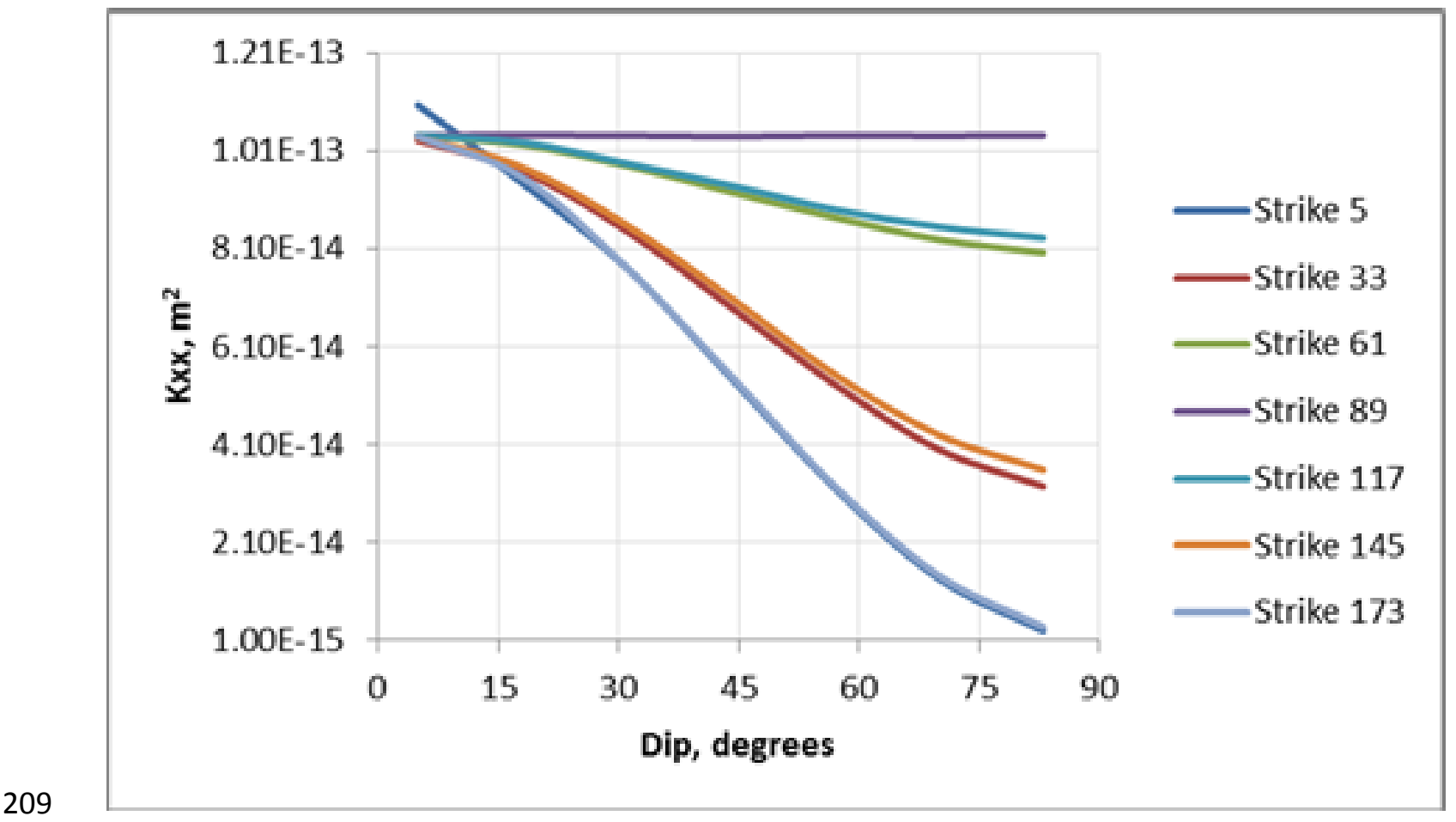

210 Figure 4: Horizontal permeability as a function of strike and dip. 


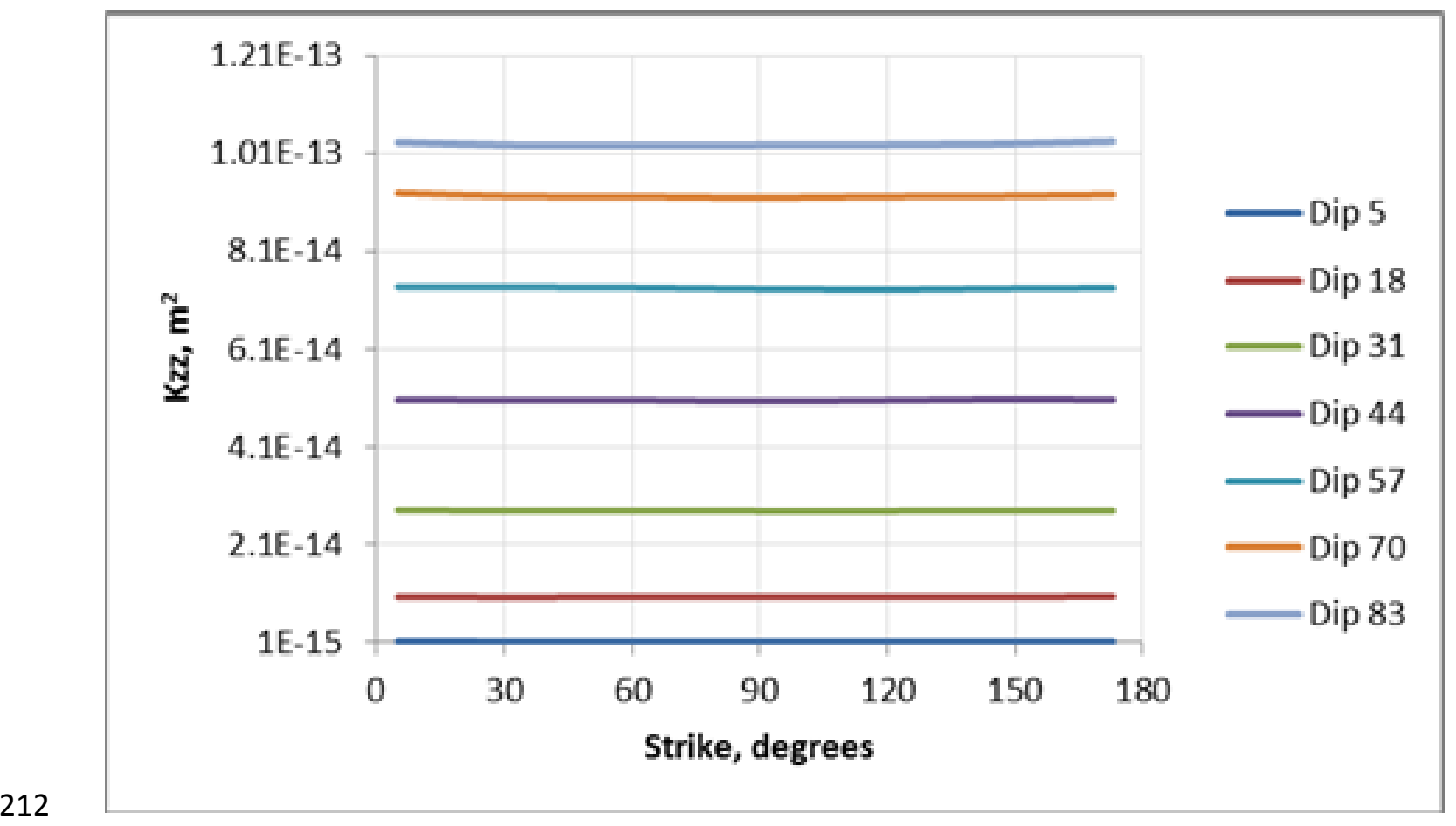

213 Figure 5: Vertical permeability as a function of strike and dip.

215 Figure 6 shows the time varying production temperature for the horizontal well configuration 216 across all combinations of strike and dip, and show that production temperature is mostly 217 insensitive for most strike and dip combinations with the exception of the cases where the dip is 218 high and the strike is closely aligned with or perpendicular to the well-pair plane. These 219 scenarios create preferential pathways that effectively reduce the volume from which heat is able 220 to be extracted, creating quicker thermal break through and drawdown. Figures 7 and 8 compare 221 the final (total time) temperature distribution of one of the best ( 222 the worst (strike $=89^{\circ}$, $\operatorname{dip}=83^{\circ}$ ) performing scenarios with respect to the thermal drawdown. 223 The earlier thermal breakthrough is clearly illustrated for the worst case scenario. 


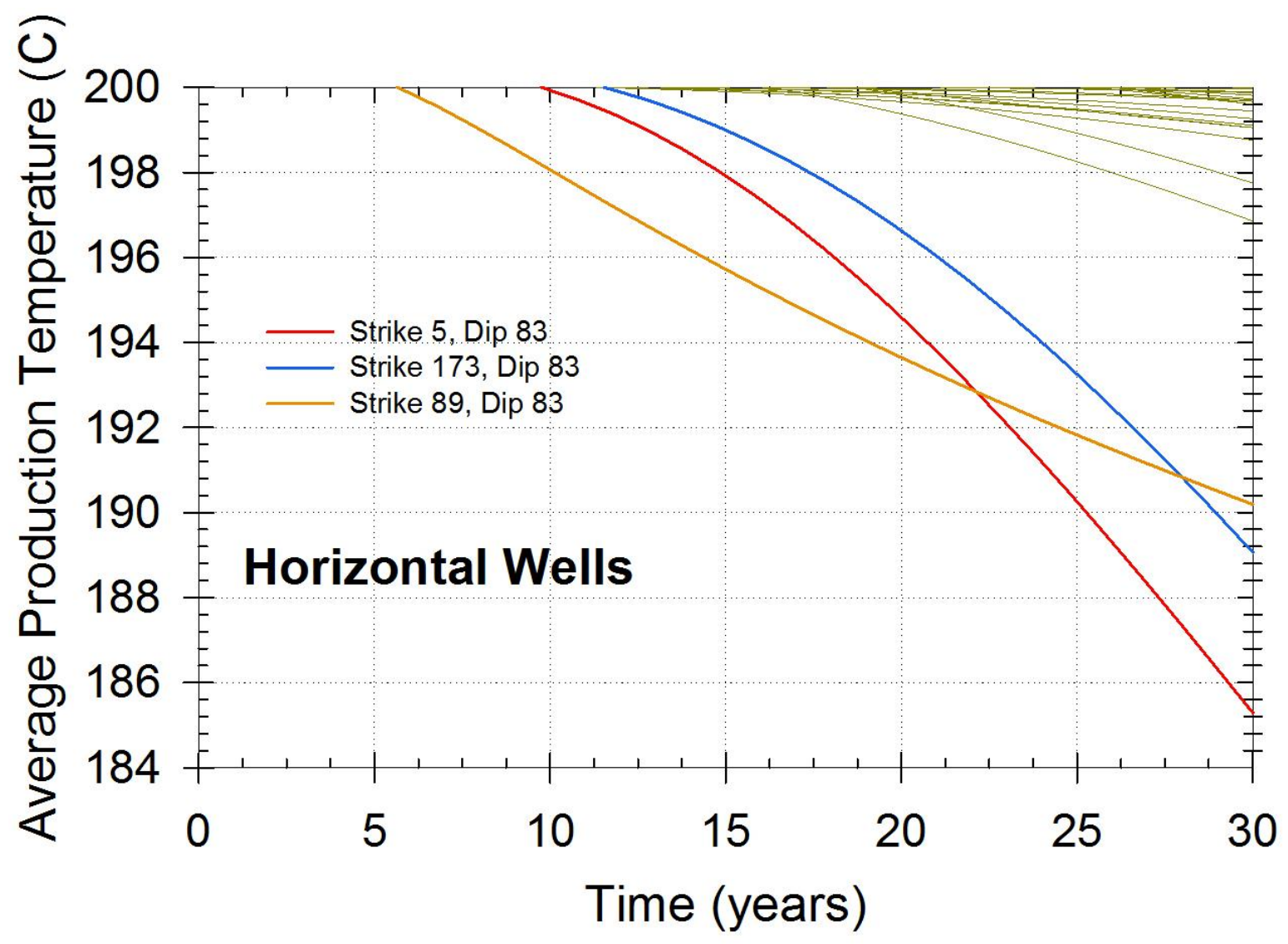

225 Figure 6: Average production temperature as a function of time for various fracture mean strike 226 and dip values. Horizontal wells with injection interval of $250 \mathrm{~m}$, well separation distance of 495 $227 \mathrm{~m}$, and injection rate of $50 \mathrm{~kg} / \mathrm{s}$. Worst performers indicated. 


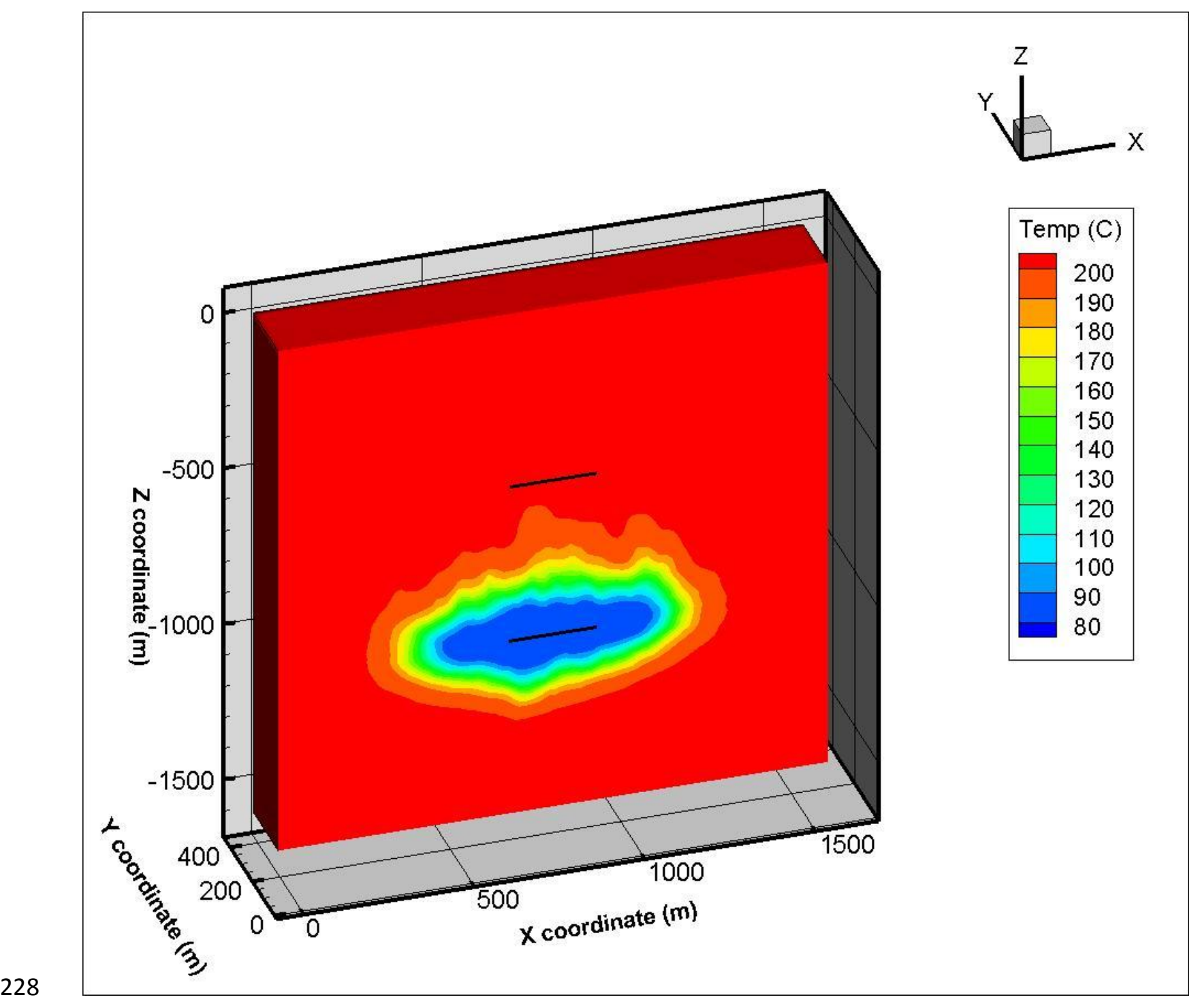

229 Figure 7: Temperature distribution at 30 years simulation time, for strike: normal distribution 230 with mean $5^{\circ}$, and dip: normal distribution with mean $18^{\circ}$. Horizontal wells with injection 231 interval of $250 \mathrm{~m}$, well separation distance of $495 \mathrm{~m}$, and injection rate of $50 \mathrm{~kg} / \mathrm{s}$. The lines 232 represent injection well (bottom) and production well (top) 

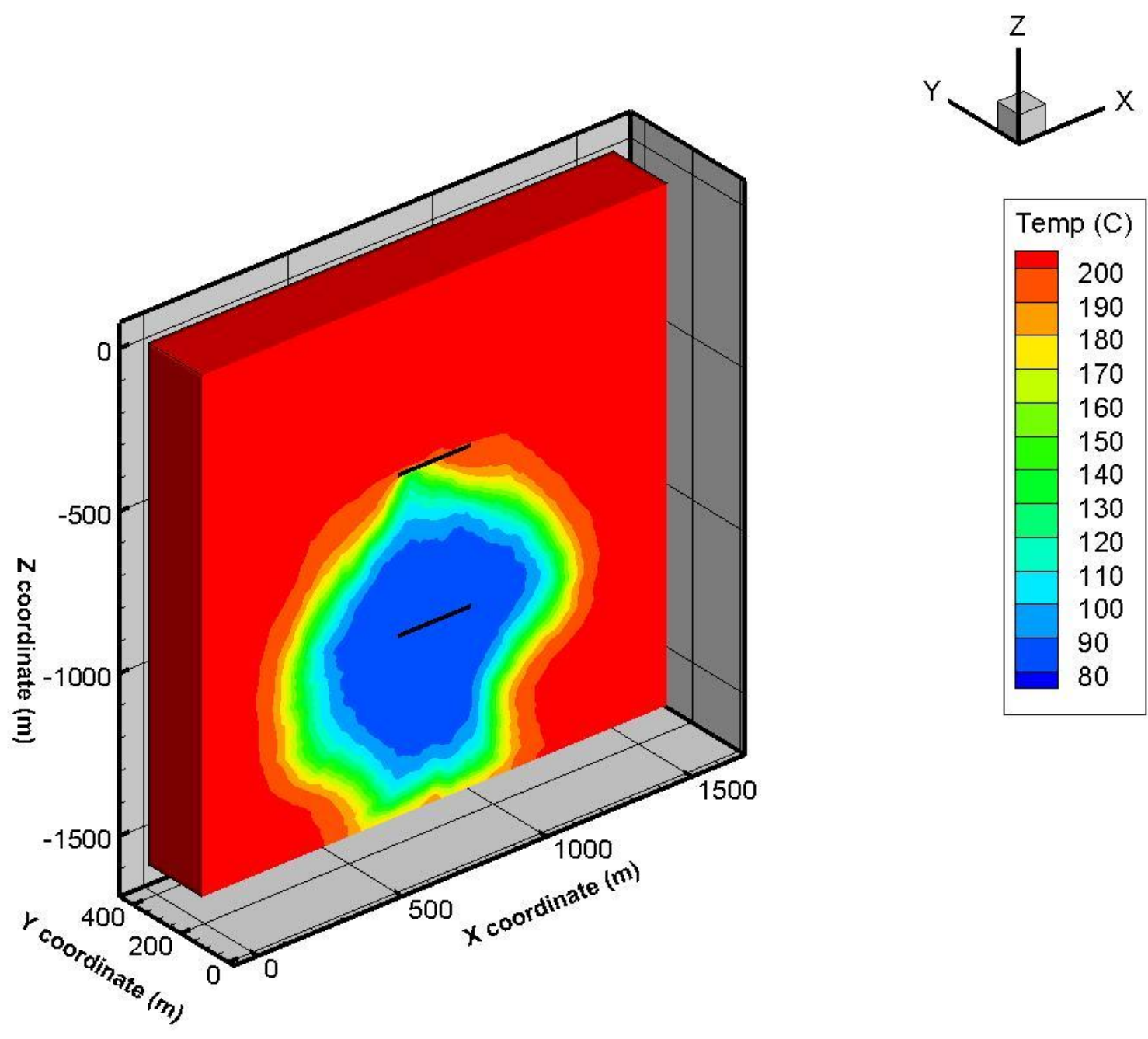

190

180

170

160

150

140

130

120

110

100

90

80

Figure 8: Temperature distribution at 30 years simulation time, for strike: normal distribution with mean $89^{\circ}$, and dip: normal distribution with mean $83^{\circ}$. Horizontal wells with injection interval of $250 \mathrm{~m}$, well separation distance of $495 \mathrm{~m}$, and injection rate of $50 \mathrm{~kg} / \mathrm{s}$. The lines represent injection well (bottom) and production well (top).

Figures 9 to 11 show the same information as Figures 6 to 8 but for the vertical well

241 configuration. The variability in performance is much higher than for the horizontal cases with,

242 the worst performers associated with shallow dips. Figures 10 and 11 compare one of the best

243 and worst case scenarios with respect to thermal drawdown. Like the horizontal case, the earlier 
244 thermal breakthrough for the worst case is easy to see. The impact of density driven flows are 245 also evident in these figures.

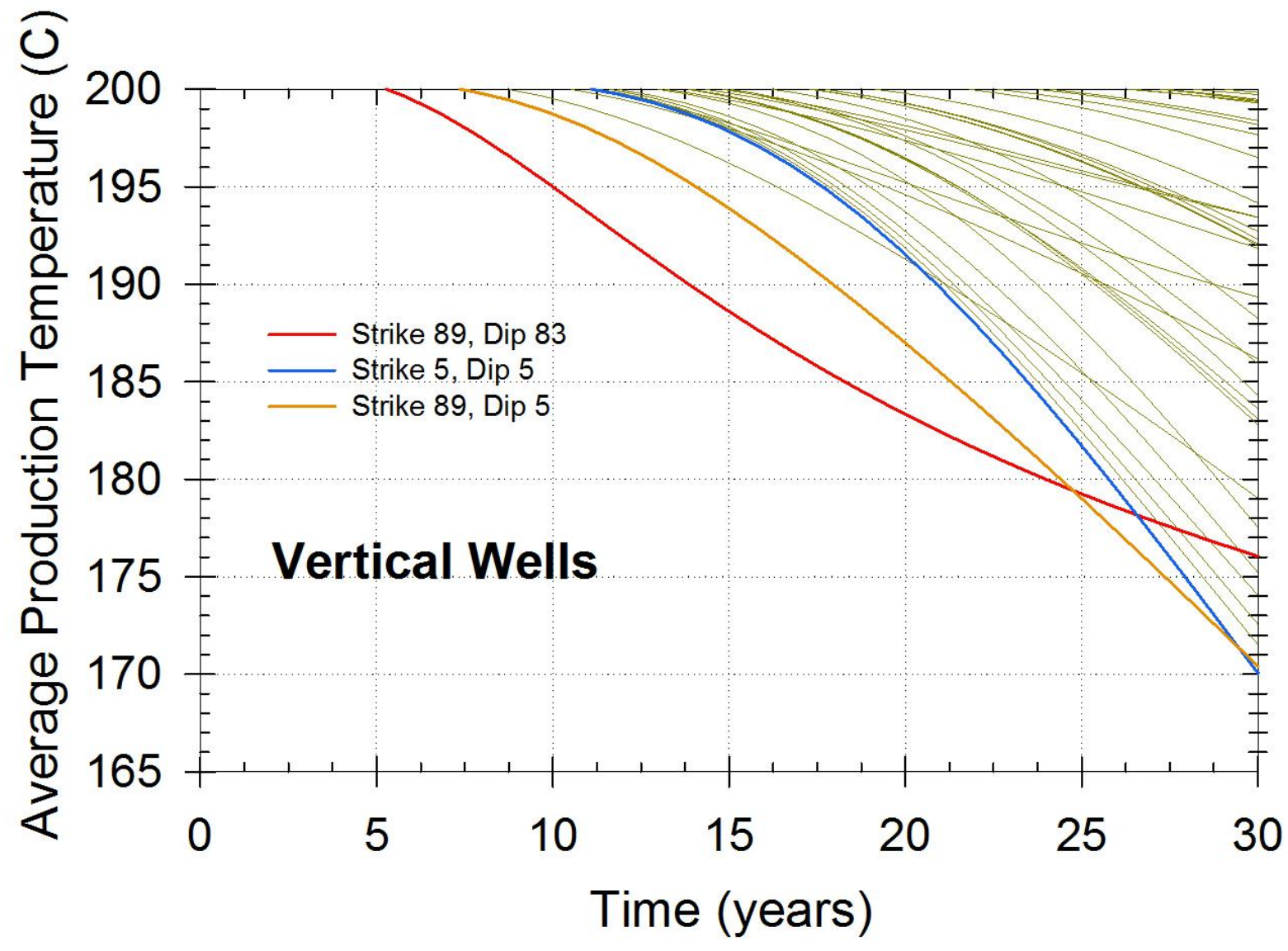

247 Figure 9: Average production temperature as a function of time for various fracture mean strike 248 and dip values. Vertical wells with injection interval of $250 \mathrm{~m}$, well separation distance of 495 $249 \mathrm{~m}$, and injection rate of $50 \mathrm{~kg} / \mathrm{s}$. Worst performers indicated. 


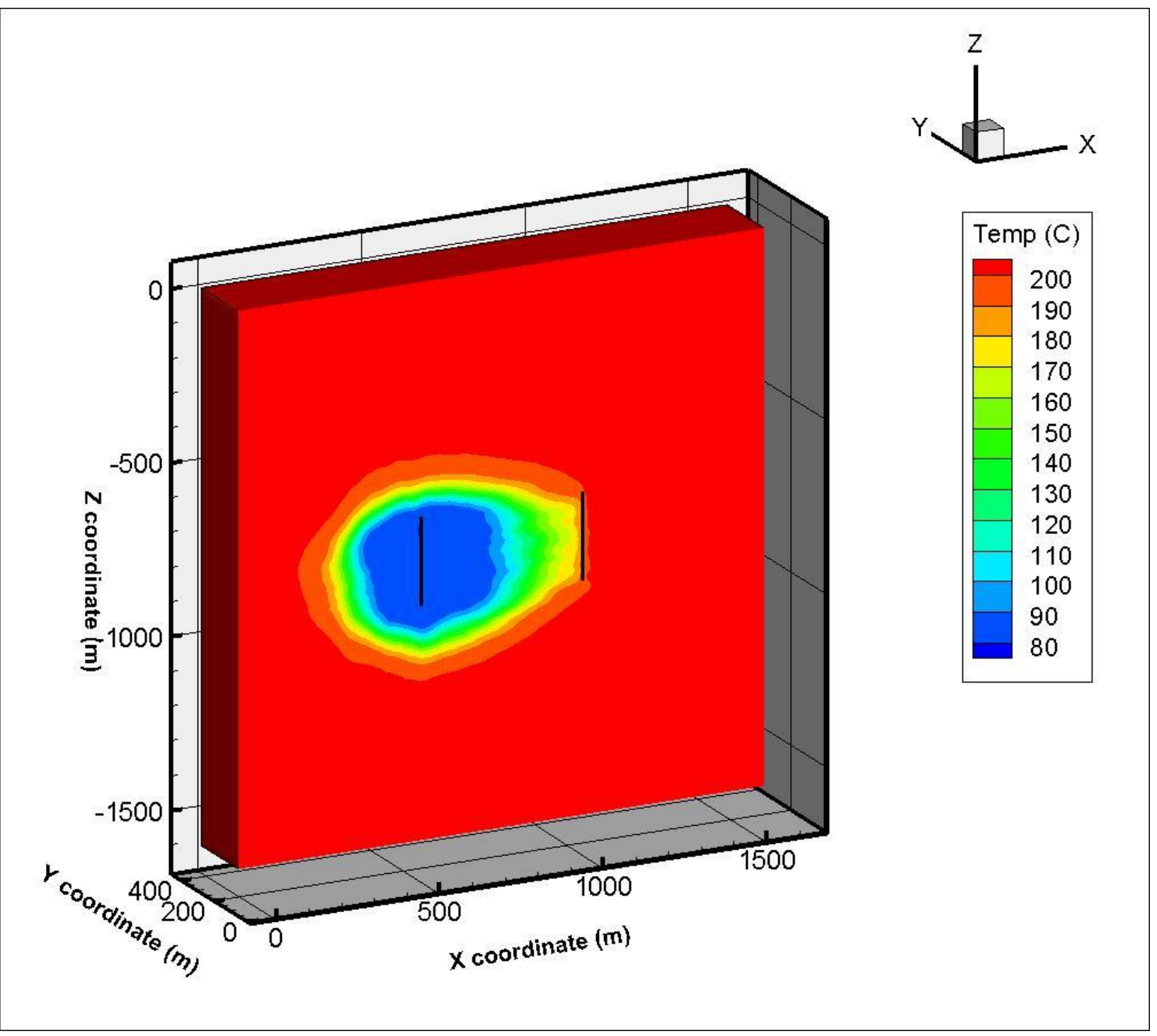

251 Figure 10: Temperature distribution at 30 years simulation time, for strike: normal distribution 252 with mean $5^{\circ}$, and dip: normal distribution with mean $18^{\circ}$. Vertical wells with injection interval 253 of $250 \mathrm{~m}$, well separation distance of $495 \mathrm{~m}$, and injection rate of $50 \mathrm{~kg} / \mathrm{s}$. The lines represent 254 injection well (right) and production well (left). 


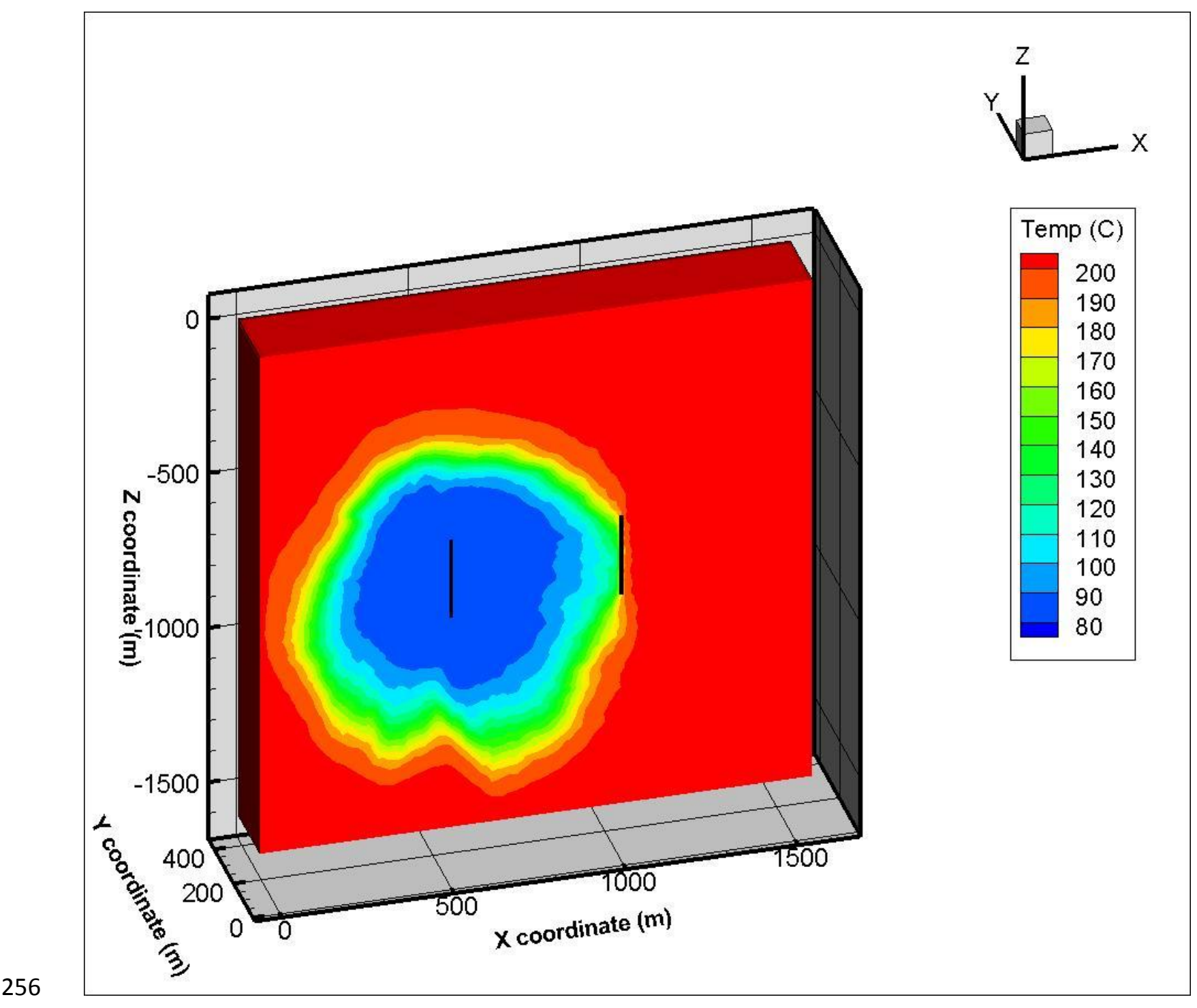

257 Figure 11: Temperature distribution at 30 years simulation time, for strike: normal distribution 258 with mean $89^{\circ}$, and dip: normal distribution with mean $83^{\circ}$. Vertical wells with injection interval 259 of $250 \mathrm{~m}$, well separation distance of $495 \mathrm{~m}$, and injection rate of $50 \mathrm{~kg} / \mathrm{s}$. The lines represent 260 injection well (right) and production well (left).

262 Figure 12 shows a three-dimensional plot of the final production temperatures as a function of 263 strike and dip for the horizontal well configuration. The drop in thermal performance at strike 264 angles that are multiples of $90^{\circ}$, and then only at high dip angles is clearly evident. Outside of 265 these strike and dip angles, the horizontal wells show little thermal drawdown over time. Figure 
13 shows a three-dimensional plot of the pressure difference between the injection and

267 production wells at 30 years as a function of strike and dip. Note that the difference in pressure

268 develops during the first year of injection and remains relatively constant during the flowing

269 period of time. The figure shows a strong correlation between pressure difference and dip (i.e.

270 vertical permeability) with an exponential-like increase at low dip (low vertical permeability)

271 values. Very little correlation is indicated between pressure difference and fracture strike. High

272 pressure differences can influence the pumping requirements for the system, which in turn

273 increases operating costs, energy requirements, and the LCOE.
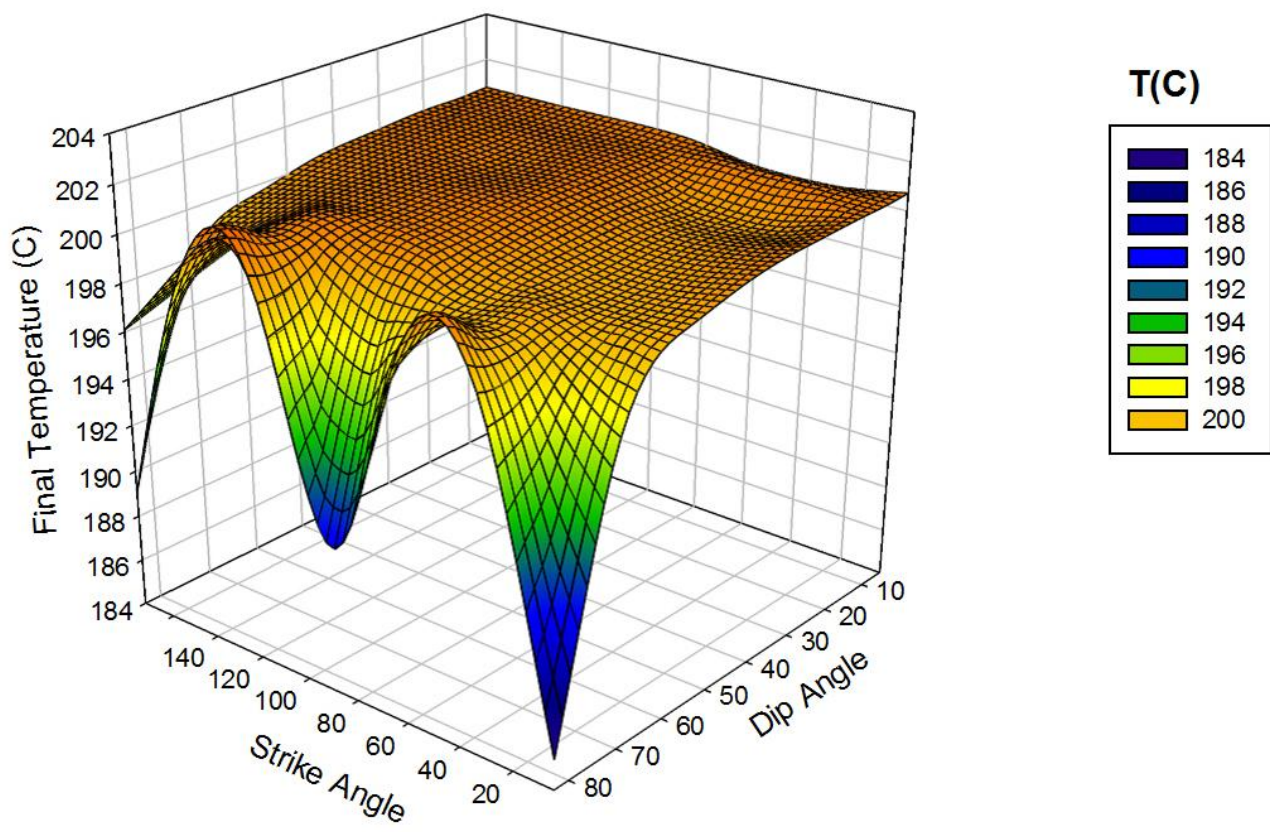

275 Figure 12: Production Temperature as a function of fracture mean dip and strike, at total 276 simulation time of 30 years. Horizontal wells with injection interval of $250 \mathrm{~m}$, well separation 277 distance of $495 \mathrm{~m}$, and injection rate of $50 \mathrm{~kg} / \mathrm{s}$. 


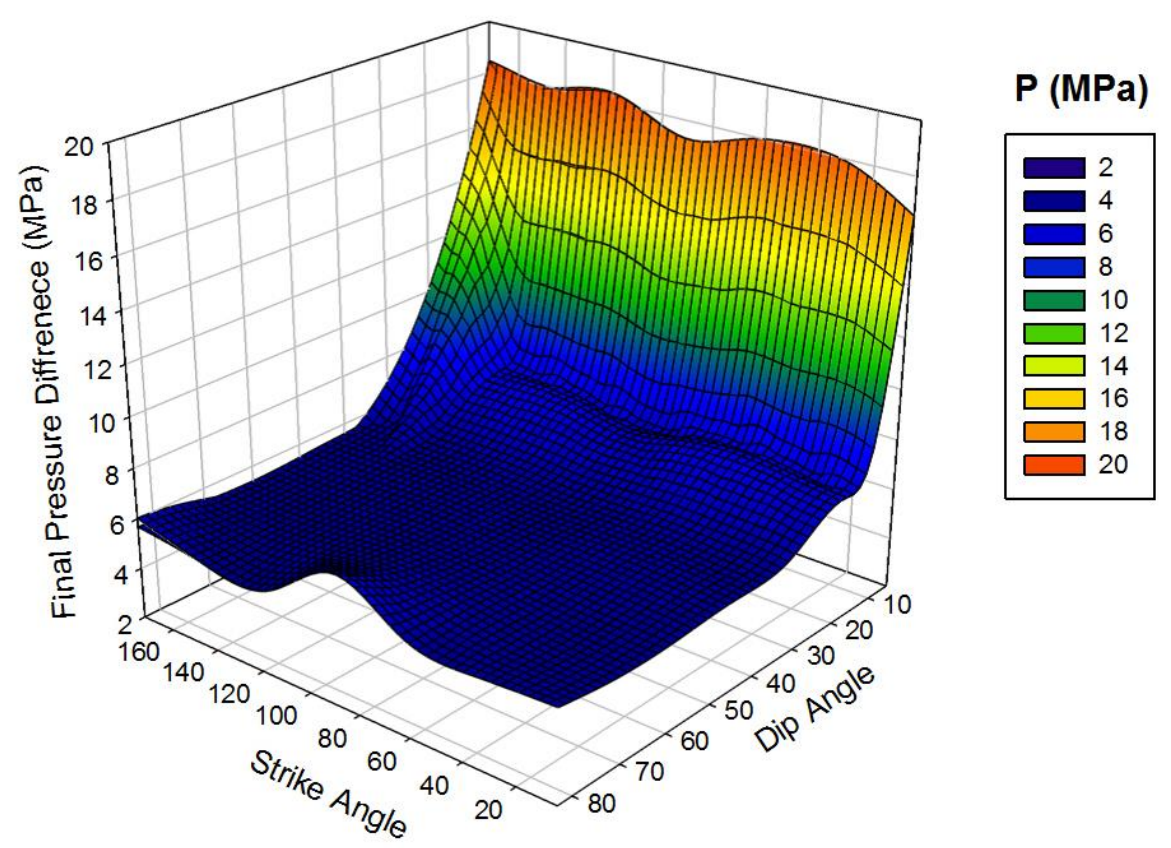

279

280 Figure 13: Pressure difference between injection and production wells as a function of fracture 281 mean dip and strike, at total simulation time of 30 years. Horizontal wells with injection interval 282 of $250 \mathrm{~m}$, well separation distance of $495 \mathrm{~m}$, and injection rate of $50 \mathrm{~kg} / \mathrm{s}$.

Figure 14 shows a three-dimensional plot of the final production temperature as a function of strike and dip for the vertical well configuration. The figure shows a strong correlation at lower dip angles for all strike values, and for all dip angles when the strike is close to $90^{\circ}$. Figure 15

287 shows a three-dimensional plot of the pressure difference between the injection and production 288 wells at 30 years as a function of strike and dip. The figure shows a strong correlation between 289 pressure difference and dip at high dip values for strike values of $5^{\circ}, 89^{\circ}$ and $173^{\circ}$ but is 290 otherwise mostly insensitive to the fracture orientation. Note that for the vertical well 291 configuration, the highest pressure differences are still less than the lowest pressure differences 292 associated with the horizontal well configuration. 


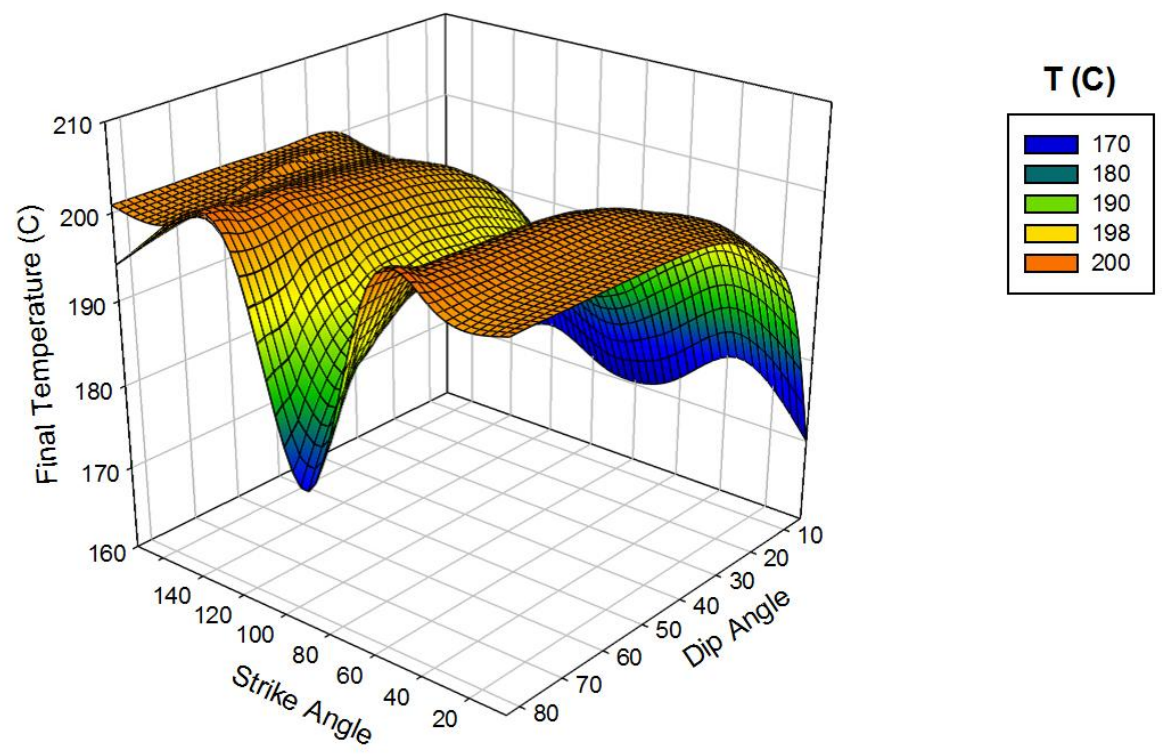

293

294 Fig 14. Production Temperature as a function of mean dip and strike, at total simulation time of 29530 years. Vertical wells with injection interval of $250 \mathrm{~m}$, well separation distance of $495 \mathrm{~m}$, and 296 injection rate of $50 \mathrm{~kg} / \mathrm{s}$. 


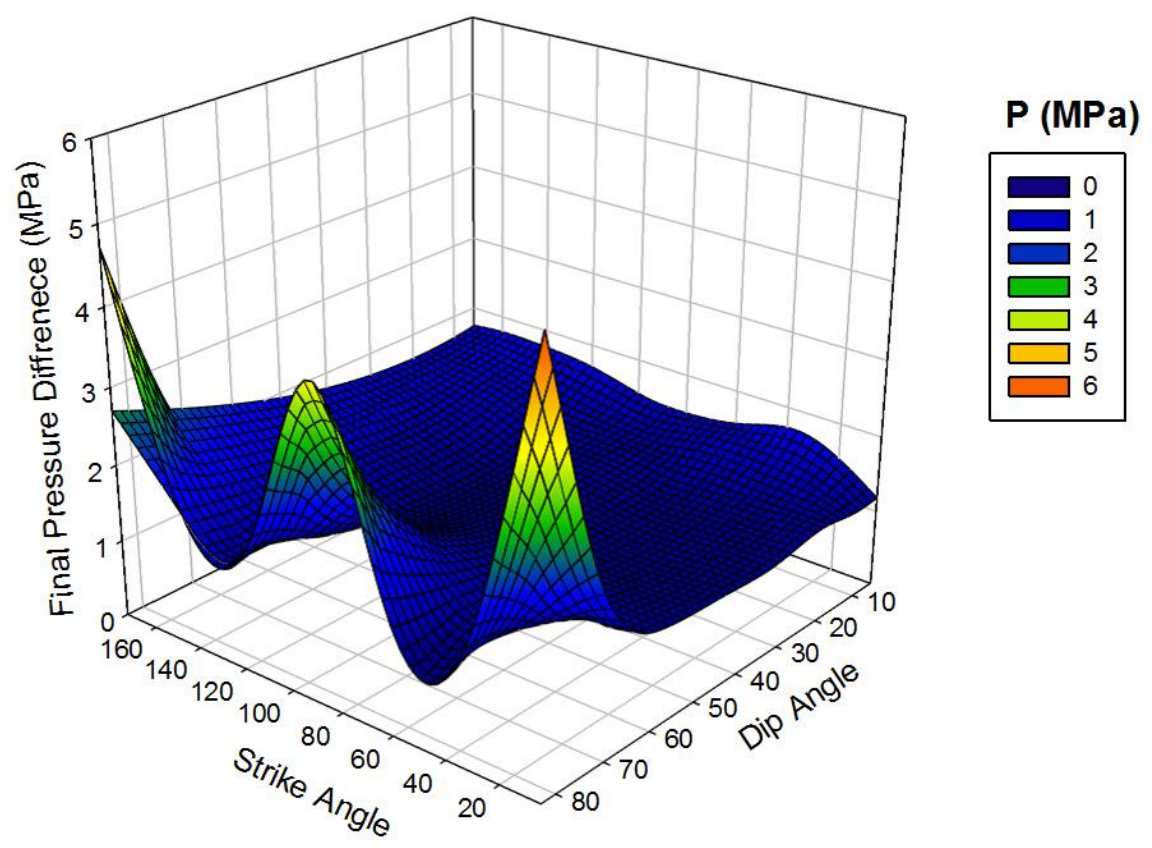

298

299 Fig 15. Pressure difference between injection and production wells as a function of fracture mean 300 dip and strike, at total simulation time of 30 years. Vertical wells with injection interval of 250 $301 \mathrm{~m}$, well separation distance of $495 \mathrm{~m}$, and injection rate of $50 \mathrm{~kg} / \mathrm{s}$.

303 To examine the effect of well separation distance, the worst performing scenarios for each of the 304 well configurations were simulated using a separation of $600 \mathrm{~m}$, versus the $495 \mathrm{~m}$ for the base 305 case. The rest of the input data are the same as above. Simulation results are shown in Figures 16 306 and 17. In both cases, increasing the separation distance improved the thermal performance over 307 time. More improvement was observed for the vertical wells case. 


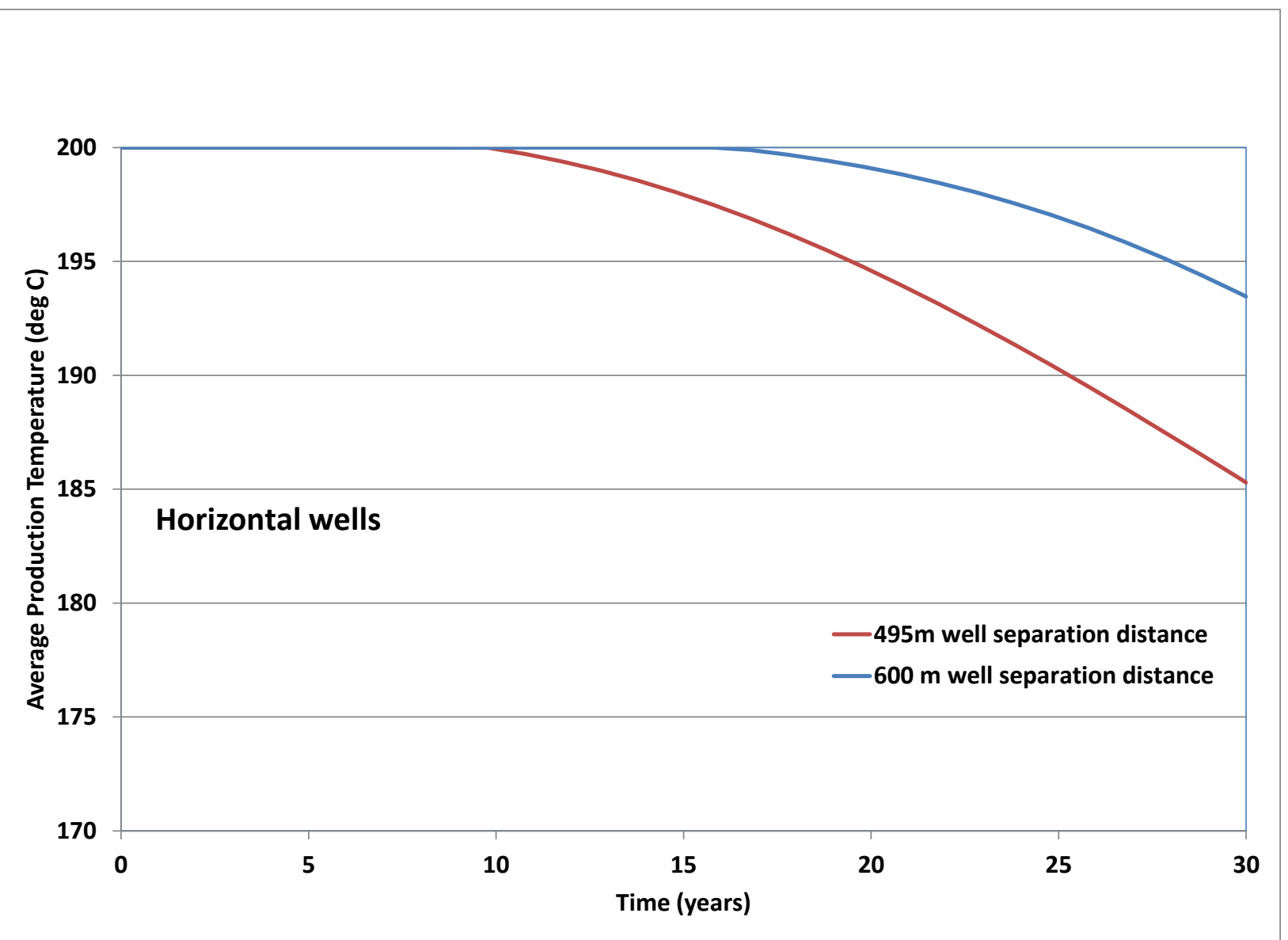

309 Figure 16: Average production temperature as a function of time for fracture mean strike of $5^{\circ}$ 310 and dip of $83^{\circ}$. Horizontal wells with injection interval of $250 \mathrm{~m}$, and injection rate of $50 \mathrm{~kg} / \mathrm{s}$. 311 Effect of well separation distance. 


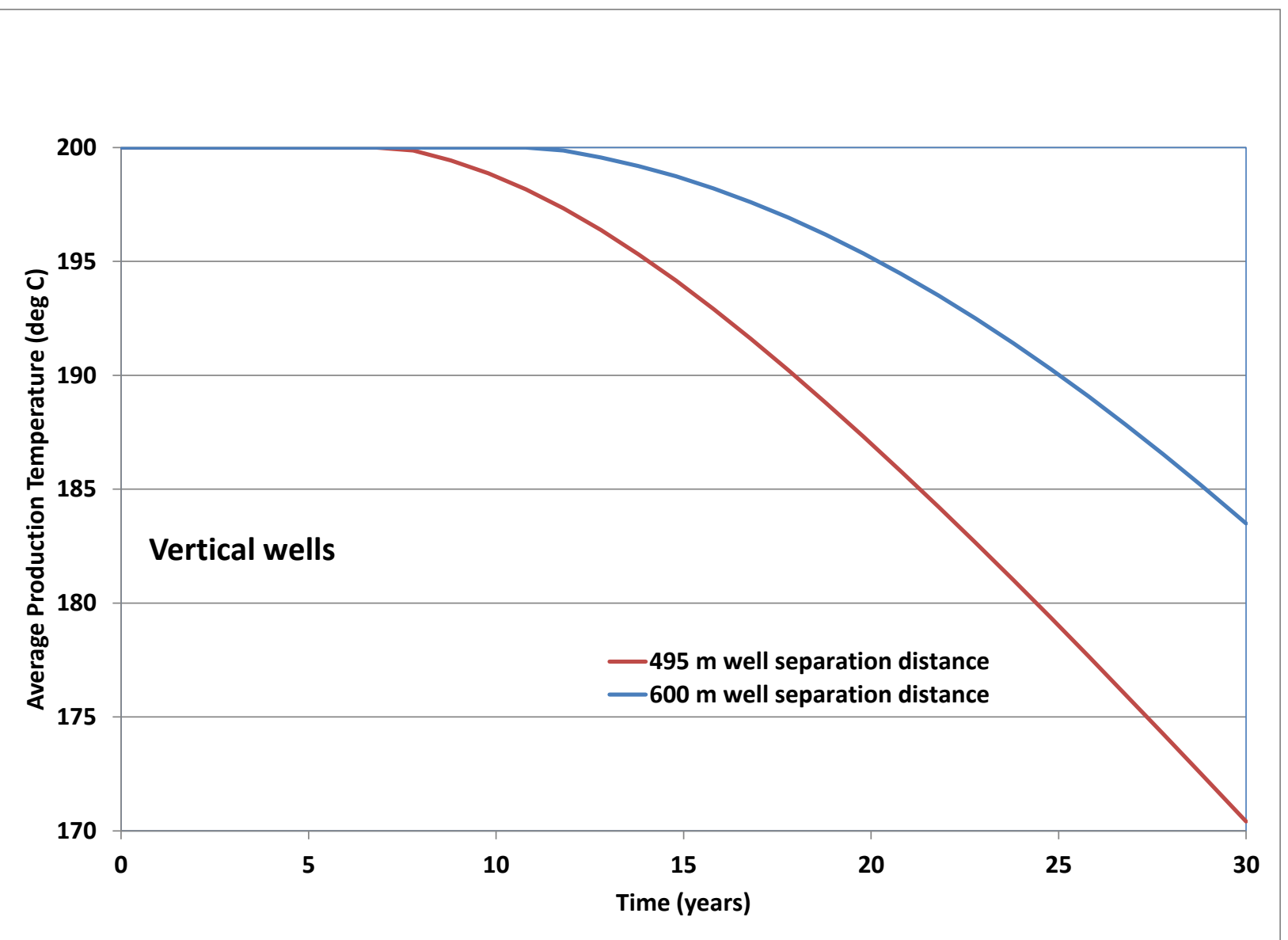

313 k 17: Average production temperature as a function of time for fracture mean strike of $89^{\circ}$ and 314 dip of $5^{\circ}$. Vertical wells with injection interval of $250 \mathrm{~m}$, and injection rate of $50 \mathrm{~kg} / \mathrm{s}$. Effect of 315 well separation distance.

\section{Conclusions}

318 The modeling study presented in this article uses the FCM approach of fracture representation to 319 identify parameters of importance to heat extraction in EGS applications. The simulation uses 320 doublet horizontal and vertical wells with selected injection interval, well separation distance and 321 injection rate values. The central part of the current study examines the influence of fracture 322 orientation on production temperature of EGS wells. 
323 The results show that there is a larger set of fracture orientations that negatively impact thermal 324 drawdown for the vertical well configuration than for the horizontal configuration. With regards 325 to thermal performance, the horizontal well configurations were nearly insensitive to strike or dip 326 with the exception of cases with high dip angles. For the vertical well configuration, the best

327 performing fracture orientations are limited to high dip angles in combination with low and high 328 strike angles. With regards to the pressure difference between the injection and production wells, 329 which in this case is used as an indicator of the pumping requirements, the vertical well 330 configuration performed best, with the highest pressure difference being lower than the lowest 331 pressure difference for the horizontal configuration.

332 From a risk perspective, the implications of these results are significant. Since risk is also a 333 function of uncertainty (Lowry et al., 2014), reducing the uncertainty with regards to thermal and 334 economic performance of an EGS site is paramount if investments are to be made in this 335 promising technology. These results show that the horizontal well configuration is the most 336 consistent performer for both thermal drawdown and pumping requirements when the dip angle 337 is bounded between 30 and 70 degrees. The fact the horizontal configuration is insensitive to the 338 strike angle reduces the need to characterize that parameter in the field and provides greater 339 flexibility for well placement and other surface facilities.

340 Glossary

341

342 EGS Enhanced Geothermal Systems

343 FCM Fracture Continuum Method 


\section{5}

346

347

348

349

350

351

352

353

354

355

356

357

358

359

360

361

362

363

364

365

366

367

368

\section{Acknowledgements}

Sandia National Laboratories is a multi-program laboratory managed and operated by Sandia Corporation, a wholly owned subsidiary of Lockheed Martin Corporation, for the U.S. Department of Energy's National Nuclear Security Administration under contract DE-AC0494AL85000. SAND2015-7093J.

Bachler, D., and Kohl, T. (2005). "Coupled Thermal-Hydraulic-Chemical Modeling of Enhanced Geothermal Systems”, Geophys. J. Int., 161, 533-548.

\section{References}

Bear, J., (1972). "Dynamics of Fluids in Porous Media”, 761 pp. New York: American Elsevier Publishing Co., (also Dover Publ., New York, 761 pp., 1988).

Freeze, R.A., and Cherry, J.A., (1979,). "Groundwater", Englewood Cliffs, NJ, Prentice-Hall, 604 pp.

Chen, M., Bai, M., Roegiers, J.-C. (1999). "Permeability Tensors of Anisotropic Fracture Networks", Mathematical Geology, 31, No. 4.

Cheng, A.H.-D., Ghassemi, A., Detournay, E. (2001). "Integral equation solution of teat extraction from a fracture in hot rock", International Journal for Numerical and Analytical Methods in Geomechanics, 25, 1327-1338. 
Doe, T., McLaren, R., and Dershowitz, W. (2014). "Discreete Fracture Network Simulations of Enhanced Geothermal Systems", Proceedings, 39-th Workshop on Geothermal Reservoir Engineering, Stanford University, Stanford, California, February 24-26, 2014, SGP-TR-202.

Ghassemi, A., Tarasovs, S., Cheng, A.H.-D. (2003). “An integral equation solution for threedimensional heat extraction from planar fracture in hot dry rock", International Journal for Numerical and Analytical Methods in Geomechanics, 27, 989-1004.

Gringarten, W.A., Witherspoon, A.P., and Ohnishi, Y. (1975). “Theory of Heat Extraction from Hot Dry Rock”, Journal of Geophysical Research, 80, 1120-1124.

Gringarten, A.C., Sauty, J.P. (1975). "A theoretical study of Heat Extraction from Aquifers with Uniform Regional Flow”, Journal of Geophysical Research, 80(35), 4956-4962.

Hao, Y., Fu, P., and Carrigan, C. R. (2013). "Application of Dual-Continuum Model for Simulation of Fluid Flow and Heat Transfer in Fractured Geothermal Reservoirs", Proceedings, 38-th Workshop on Geothermal Reservoir Engineering, Stanford University, Stanford, California, February 11-13, 2013, SGP-TR-198.

Juliusson, E., and Horne, R. (2010). "Characterization of Fractures in geothermal Reservoirs", Proceedings, World Geothermal Congress, Bali, Indonesia, 25-29 April, 2010. 
392 Kalinina, E, McKenna, S.A., Hadgu, T., Lowry, T.S. (2012a). "Analysis of the Effects of 393 Heterogeneity on Heat Extraction in an EGS Represented with the Continuum Fracture Model", Proceedings, 37-th Workshop on Geothermal Reservoir Engineering, Stanford University, Stanford, California, January 30 - February 1, 2012, SGP-TR-194, 436-445.

Kalinina, E, McKenna, S.A., Klise, K., Hadgu, T., Lowry, T.S. (2012b).’Incorporating Complex 398 Three-Dimensional Fracture Network into Geothermal Reservoir Simulations", Geothermal Resources Council Transactions, 36,

400

401

402

403

Kalinina, Klise, K., E, McKenna, S.A., Hadgu, T., Lowry, T.S. (2014a).”Applications of Fractured Continuum Model to Enhanced Geothermal System Heat Extraction Problems”, SpringerPlus 2014, 3:110.

404

405 Kalinina, E, McKenna, S.A., Hadgu, T., Lowry, T.S. (2014b). "Thermal Performance of 406

410 Lowry, T.S., Kalinina, Hadgu, T., Klise, K. A., and Malczynski, L. A. (2014). "Economic 411 Valuation of Directional Wells for EGS Heat Extraction", Proceedings, 39-th Workshop on 412 Geothermal Reservoir Engineering, Stanford University, Stanford, California, February 2426, 2014, SGP-TR-202. 
415 McKenna, S. A. and P. C. Reeves (2006). "Fractured Continuum Approach to Stochastic 416 Permeability Modeling” in T. C. Coburn, J. M. Yarus, and R. L. Chambers, (eds.), Stochastic 417 Modeling and Geostatistics: Principles, Methods, and Case Studies, Volume I, American 418 Association of Petroleum Geologists, Tulsa, Oklahoma, pp. 173-186.

Shiozawa, S., and McClure, M (2002). "EGS Designs with Horizontal Wells, Multiple Stages, and Proppant", Proceedings, 39-th Workshop on Geothermal Reservoir Engineering, Stanford University, Stanford, California, February 24-26, 2014, SGP-TR-202.

424 Tsang, Y., Tsang, C., Hale, F., Dverstorp. B. (1996). "Modeling heat extraction from hot dry 425 rock in a multi-well system”, Applied Thermal Engineering, 29, 1676-1681.

427 Yang, S., and Yeh, H. (2009). "Integral equation solution of teat extraction from a fracture in hot 428 rock", International Journal for Numerical and Analytical Methods in Geomechanics, 25, $429 \quad 1327-1338$.

431 Zyvoloski, G.A., B.A. Robinson, Z.V. Dash, and L.L. Trease (1997). "Summary of the Models 432 and Methods for the FEHM Application - A Finite-Element Heat- and Mass-Transfer Code”, LA-13307-MS, Los Alamos, New Mexico: Los Alamos National Laboratory. 